\title{
Hippocampal Disinhibition Reduces Contextual and Elemental Fear Conditioning While Sparing the Acquisition of Latent Inhibition
}

\author{
Stuart A. Williams, ${ }^{1,3}$ Miriam Gwilt, ${ }^{1,3}$ - Rebecca Hock, ${ }^{1,3}$ Charlotte Taylor, ${ }^{1,3}$ Joanna Loayza, ${ }^{1,3}$ \\ Carl W. Stevenson, ${ }^{2,3}$ Helen J. Cassaday, ${ }^{1,3}$ and Tobias Bast ${ }^{1,3}$
}

https://doi.org/10.1523/ENEURO.0270-21.2021

${ }^{1}$ School of Psychology, University of Nottingham, Nottingham NG7 2RD, United Kingdom, ${ }^{2}$ School of Biosciences, University of Nottingham, Sutton Bonington LE12 5RD, United Kingdom, and ${ }^{3}$ Neuroscience@Nottingham, University of Nottingham, Nottingham NG7 2RD, United Kingdom

\begin{abstract}
Hippocampal neural disinhibition, i.e., reduced GABAergic inhibition, is a key feature of schizophrenia pathophysiology. The hippocampus is an important part of the neural circuitry that controls fear conditioning and can also modulate prefrontal and striatal mechanisms, including dopamine signaling, which play a role in salience modulation. Consequently, hippocampal neural disinhibition may contribute to impairments in fear conditioning and salience modulation reported in schizophrenia. Therefore, we examined the effect of ventral hippocampus (VH) disinhibition in male rats on fear conditioning and salience modulation, as reflected by latent inhibition (LI), in a conditioned emotional response (CER) procedure. A flashing light was used as the conditioned stimulus (CS), and conditioned suppression was used to index conditioned fear. In experiment 1, VH disinhibition via infusion of the GABA-A receptor antagonist picrotoxin before CS pre-exposure and conditioning markedly reduced fear conditioning to both the CS and context; LI was evident in saline-infused controls but could not be detected in picrotoxin-infused rats because of the low level of fear conditioning to the CS. In experiment 2, VH picrotoxin infusions only before CS pre-exposure did not affect the acquisition of fear conditioning or LI. Together, these findings indicate that VH neural disinhibition disrupts contextual and elemental fear conditioning, without affecting the acquisition of LI. The disruption of fear conditioning resembles aversive conditioning deficits reported in schizophrenia and may reflect a disruption of neural processing both within the hippocampus and in projection sites of the hippocampus.
\end{abstract}

Key words: conditioning; fear; GABA; hippocampus; rat; salience

\section{Significance Statement}

Hippocampal disinhibition, reduced GABAergic inhibition, is a feature of schizophrenia, but how this contributes to psychological deficits remains to be clarified. Patient studies using classical-conditioning assays show aberrant salience allocation to stimuli that healthy participants have learnt to ignore, as well as reduced fear conditioning, which have been linked to psychosis and negative symptoms, respectively. These impairments may be related to hippocampal disinhibition because the hippocampus modulates neural substrates of salience allocation and is part of the fear-conditioning neural circuit. Combining selective pharmacological manipulation of the hippocampus with a conditioning assay in rats, we found hippocampal disinhibition disrupted fear conditioning, without evidence for aberrant salience allocation. This suggests hippocampal disinhibition contributes to fear conditioning deficits in schizophrenia.

\footnotetext{
Received June 14, 2021; accepted October 13, 2021; First published January 3, 2022.

The authors declare no competing financial interests.
}

Author contributions: S.A.W., C.W.S., H.J.C., and T.B. designed research; S.A.W., M.G., R.H., C.T., and J.L. performed research; S.A.W. analyzed data; S.A.W. and T.B. wrote the paper. 


\section{Introduction}

Hippocampal hyperactivity and neural disinhibition, i.e., reduced GABAergic inhibition, are key characteristics of schizophrenia pathophysiology and have been implicated in behavioral deficits characterizing the disorder (Friston et al., 1992; Lisman et al., 2008; Tamminga et al., 2010; Tregellas et al., 2014; Heckers and Konradi, 2015; Lieberman et al., 2018). This hyperactivity is most evident in the anterior hippocampus (McHugo et al., 2019), corresponding to the rodent ventral hippocampus $(\mathrm{VH}$; Strange et al., 2014). Hippocampal disinhibition might contribute to behavioral impairments by disrupting neural processing both within the hippocampus, where regional disinhibition (by local microinfusion of the GABA-A receptor antagonist picrotoxin) causes aberrant burst firing (McGarrity et al., 2017) and alters oscillatory activity (Gwilt et al., 2020) in rats, and in hippocampal projection sites (Lodge and Grace, 2011; Bast et al., 2017; Katzel et al., 2020). Here, we tested whether hippocampal disinhibition contributes to deficits in latent inhibition (LI) and fear conditioning, which have been reported in schizophrenia.

$\mathrm{LI}$ refers to the reduced conditioning to a conditioned stimulus (CS), to which participants had been pre-exposed (PE) without consequence, and LI deficits have been reported in acute schizophrenia (Baruch et al., 1988; Gray et al., 1995; Rascle et al., 2001). One interpretation of reduced $\mathrm{LI}$ is that this reflects aberrant salience allocation to a stimulus that healthy participants had learned to ignore, and these findings contributed to the view that aberrant salience allocation is a key feature of schizophrenia and underlies psychotic symptoms (Gray et al., 1991; Kapur, 2003; Howes et al., 2020). Additionally, patients with schizophrenia show reduced aversive conditioning (Jensen et al., 2008; Holt et al., 2009; Romaniuk et al., 2010), which has been associated with negative symptoms (Holt et al., 2012).

The neural processes that underlie deficits in $\mathrm{LI}$ and aversive conditioning can be studied using rodent models. Permanent lesion studies in rats indicated that the hippocampus is not required for $\mathrm{LI}$, although the adjacent entorhinal cortex and fibers passing through the hippocampus do play a role (Weiner, 2003); moreover, temporary inactivation studies indicated that the ventral subiculum may normally contribute to LI formation during pre-exposure (Peterschmitt et al., 2005, 2008). Interestingly, although NMDA-induced VH lesions spared LI acquisition, VH stimulation by local NMDA infusion moderately attenuated LI.

This work was supported by the Biotechnology and Biological Sciences Research Council (BBSRC) Doctoral Training Programme (DTP) Grant BB/ M008770/1, project 1804204 at the University of Nottingham (Standard DTP PhD Studentships to S.A.W. and R.H.; CASE PhD studentships to M.G. and C. T.) and the Medical Research Council (MRC) Integrated Midlands Partnership for Biomedical Training (IMPACT; PhD studentship to J.L.)

Correspondence should be addressed to Stuart A. Williams at stuwilliams08@gmail.com or Tobias Bast at tobias.bast@nottingham.ac.uk.

https://doi.org/10.1523/ENEURO.0270-21.2021

Copyright (c) 2022 Williams et al.

This is an open-access article distributed under the terms of the Creative Commons Attribution 4.0 International license, which permits unrestricted use, distribution and reproduction in any medium provided that the original work is properly attributed.
However, this could partly have reflected reduced aversive conditioning (Pouzet et al., 2004). Although processing within the hippocampus could play a limited role in LI, VH stimulation and neural disinhibition might disrupt LI by stimulating dopamine release in ventral striatum and medial prefrontal cortex (mPFC; Legault et al., 2000; Mitchell et al., 2000; Floresco et al., 2001; Peleg-Raibstein et al., 2005; Bast, 2011). Increased dopamine function, especially in the ventral striatum (Joseph et al., 2000; Young et al., 2005; Nelson et al., 2011), but also the mPFC (Morrens et al., 2020), has been shown to disrupt $\mathrm{LI}$ at conditioning. Additionally, $\mathrm{VH}$ disinhibition disrupted mPFC-dependent attention, presumably by way of strong hippocampo-mPFC projections (McGarrity et al., 2017; Tan et al., 2018), and could also disrupt $\mathrm{LI}$ acquisition during CS pre-exposure, which has been shown to require the mPFC (Lingawi et al., 2018). Apart from $\mathrm{LI}, \mathrm{VH}$ disinhibition may also disrupt aversive conditioning itself, because the $\mathrm{VH}$ contributes to fear conditioning (Bannerman et al., 2004; Fanselow and Dong, 2010) and VH stimulation by NMDA was found to disrupt fear conditioning (Zhang et al., 2001).

Therefore, we tested the hypothesis that $\mathrm{VH}$ disinhibition would disrupt the acquisition of $\mathrm{LI}$ and fear conditioning in rats. We determined the effect of $\mathrm{VH}$ neural disinhibition via local microinfusion of the GABA-A receptor antagonist picrotoxin (McGarrity et al., 2017) on LI and fear conditioning, using a conditioned emotional response (CER) procedure with a CS pre-exposure stage (Nelson et al., 2011). Experiment 1 examined $\mathrm{VH}$ disinhibition during both pre-exposure and conditioning; this markedly reduced fear conditioning to the CS, so we were unable to examine changes in LI. Therefore, experiment 2 examined the effect of hippocampal disinhibition during pre-exposure only on the formation of LI.

\section{Materials and Methods}

\section{Rats}

Overall, we used 104 male Lister Hooded rats (Charles River), weighing 310-400 g (9-12 weeks old) at the start of experiments. In experiment 1,72 rats were tested in three batches of 24 rats. Experiment 2 used 32 rats in a single batch. See section below, Experimental design, for further detail and for sample size justifications.

Rats were housed in groups of four in individually ventilated "double decker" cages (462 × $403 \times 404$ mm; Techniplast) with temperature and humidity control $\left(21 \pm 1.5^{\circ} \mathrm{C}, 50 \pm 8 \%\right)$ and an alternating 12/12 $\mathrm{h}$ light/dark cycle (lights on at 7 A.M.). Rats had ad libitum access to food (Teklad Global $18 \%$ protein diet, Harlan) throughout the study. Access to water was restricted during the CER procedure (see details below) but was available ad libitum during all other stages of the study. All rats were habituated to handling by experimenters for at least $5 \mathrm{~d}$ before any experimental procedure. All experimental procedures were conducted during the light phase and in accordance with the requirements of the United Kingdom Animals (Scientific Procedures) Act 1986, approved by the University of Nottingham's Animal Welfare and Ethical Review Board (AWERB) and run under the authority of Home Office project license 30/3357. 


\section{Stereotaxic implantation of guide cannulae into the VH}

Rats were anaesthetized using isoflurane delivered in oxygen (induced with 5\% and maintained at 1.5-3\%; flow rate $1 \mathrm{~L} / \mathrm{min}$ ) and then placed in a stereotaxic frame. A local anesthetic (EMLA cream, AstraZeneca) was applied to the ear bars to minimize discomfort. A gel was used (Lubrithal; Dechra) to prevent the eyes from drying out during surgery. After incision of the scalp, bilateral infusion guide cannula (stainless steel, 26 gauge, $8.5 \mathrm{~mm}$ below pedestal, Plastics One) were implanted through small predrilled holes in the skull. The stereotaxic coordinates for the infusions were $5.2 \mathrm{~mm}$ posterior, $\pm 4.8 \mathrm{~mm}$ lateral from the midline, and $6.5 \mathrm{~mm}$ ventral from the dura for infusions into the VH (see Fig. 1 for infusion cannula placements), based on previous studies targeting the $\mathrm{VH}$ in Lister Hooded rats (McGarrity et al., 2017). Stainless steel stylets (33 gauge, Plastics One), complete with dust cap, were placed into the guide cannula and protruded $0.5 \mathrm{~mm}$ beyond the tips of the guide cannula to prevent occlusion. Dental acrylic (flowable composite; Henry Schein Medical) and four stainless steel screws were used to fix the guide cannulae to the skull. The scalp incision was stitched around the acrylic pedestal to reduce the open wound to a minimum. All rats were injected with perioperative analgesia (Rimadyl, Large Animal Solution, Zoetis; 1:9 dilution; $0.1 \mathrm{ml} / 100 \mathrm{~g}$, s.c.). At the end of surgery, rats were injected with $1 \mathrm{ml}$ of saline (intraperitoneally) to prevent dehydration. Antibiotics were administered on the day of surgery and subsequently every $24 \mathrm{~h}$ for the duration of the study (Synulox; $140 \mathrm{mg}$ amoxicillin, $35 \mathrm{mg}$ clavulanic acid/ $\mathrm{ml} ; 0.02 \mathrm{ml} / 100$ g, s.c.; Pfizer). After surgery, rats were allowed at least $5 \mathrm{~d}$ of recovery before any further experimental procedures were conducted. During this period, rats underwent daily health checks and were habituated to the manual restraint necessary for drug microinfusions.

\section{Microinfusions into the $\mathbf{V H}$}

Rats were manually restrained throughout the infusion process. Stylets were replaced with infusion injectors (stainless steel, 33 gauge, Plastics One), which extended $0.5 \mathrm{~mm}$ below the guide cannula tips into the $\mathrm{VH}$. Injectors were connected via flexible polyethylene tubing to 5- $\mu$ I SGE microsyringes mounted on a microinfusion pump (sp200IZ, World Precision Instruments). A volume of $0.5 \mu \mathrm{l} / \mathrm{side}$ of either $0.9 \%$ sterile saline (vehicle) or picrotoxin $(150 \mathrm{ng} / 0.5 \mu \mathrm{l} / \mathrm{side}$; Sigma-Aldrich) in saline was infused bilaterally over the course of $1 \mathrm{~min}$, as in previous studies to induce neural disinhibition in the VH (McGarrity et al., 2017). The movement of an air bubble, which was included in the tubing, was monitored to ensure the solution had been successfully injected into the brain. Injectors were removed and replaced by the stylets $60 \mathrm{~s}$ after the end of infusion to allow for tissue absorption of the infusion bolus. The timing of infusions in relation to behavioral testing is described below, Experimental design.

In a previous study, the dose of picrotoxin (150 ng/ $0.5 \mu \mathrm{l} / \mathrm{side}$ ) used did not cause seizure-related behavioral signs or electrophysiological signs of hippocampal seizures in local field potential recordings in anaesthetized rats (McGarrity et al., 2017). However, picrotoxin has the potential to cause epileptiform activity in the hippocampus (Qaddoumi et al., 2014). Therefore, all rats receiving infusions were monitored carefully during and after infusion for behavioral signs potentially related to seizure development, including facial twitching, wet-dog shakes, clonic limb movement, motor convulsions, and wild jumping (Racine, 1972; Luttjohann et al., 2009).

\section{CER procedure with a pre-exposure phase to measure aversive conditioning and its $\mathrm{LI}$}

We used a CER procedure previously described by Nelson et al. (2011). The procedure, which will be described in detail below, involved water deprivation, shaping (1 d) and pretraining of the rats to drink from spouts in conditioning chambers $(5 \mathrm{~d})$, followed by pre-exposure to a light (the prospective $\mathrm{CS}$ ) in conditioning chambers [or exposure to the conditioning chamber without CS pre-exposure in the non-PE (NPE) comparison group; $1 \mathrm{~d}$ ], conditioning during which the CS was paired with an electric footshock, reshaping (1 d) to re-establish drinking after conditioning and testing ( $1 \mathrm{~d}$ ) of the lick suppression induced by CS presentation following conditioning (for an outline of the CER stages, also see Figs. 2A, 3A). Suppression of licking for water by the CS was used to measure the CER. $\mathrm{LI}$ is reflected by a reduced CER, i.e., less suppression of licking for water, in the PE as compared with the NPE group.

\section{Apparatus}

Four identical fully automated conditioning chambers including sound attenuating cases and ventilation fans (Cambridge Cognition) were used. The inner chambers consisted of a plain steel box $(25 \times 25 \times 22 \mathrm{~cm})$ with a Plexiglas door $(27 \times 21 \mathrm{~cm})$. The floor of the inner conditioning chamber comprised of a shock delivery system, consisting of $1-\mathrm{cm}$ spaced steel bars. These were positioned $1 \mathrm{~cm}$ above the lip of a 7-cm-deep sawdust tray. Mounted $5 \mathrm{~cm}$ above the grid floor was a waterspout connected to a lickometer supplied by a water pump. Licks were registered by breaking a photo beam within the spout, which triggered water delivery of $0.05 \mathrm{ml}$ per lick. The spout was only illuminated when water was available. Three wall mounted lights and the house light flashing on $(0.5 \mathrm{~s})$ and off $(0.5 \mathrm{~s})$ for $5 \mathrm{~s}$ functioned as the CS. Scrambled foot-shock of $1 \mathrm{~mA}$ intensity for $1 \mathrm{~s}$ provided the unconditioned stimulus (US). The shock was delivered through the grid floor by a constant current shock generator (pulsed voltage: output square wave $10 \mathrm{~ms}$ on, $80 \mathrm{~ms}$ off, 370-V peak under no load conditions; MISAC Systems). Stimulus control and data collection were recorded using an Acorn RISC computer programmed in basic with Arachnid extension (Cambridge Cognition).

\section{Behavioral procedure}

Water restriction. One day before behavioral testing, rats were water restricted for between 18 and $22 \mathrm{~h}$. Subsequently, they received $1 \mathrm{~h}$ and $15 \mathrm{~min}$ of ad libitum access to water in their home cages for the duration of the experiment, once daily testing was completed and in addition to access to water in the conditioning chambers. 
Shaping and pretraining. Rats were shaped for $1 \mathrm{~d}$ until all rats drank from the waterspout and were assigned an individual conditioning chamber for the whole CER procedure. Subsequently, rats were given a $15 \mathrm{~min}$ session (timed from first lick) per day for $5 \mathrm{~d}$ to drink from the waterspout. During the sessions, the waterspout was illuminated throughout, but no other stimuli were present. Total number of licks was recorded during each session to assess any pre-existing differences in drinking before infusions.

Preexposure. The PE rats received 305 -s flashing light CS presentations with an average inter-stimulus interval of $60 \mathrm{~s} \mathrm{(32-min} \mathrm{session} \mathrm{duration).} \mathrm{The} \mathrm{NPE} \mathrm{control} \mathrm{rats}$ were confined to the conditioning chamber for an identical period of time without receiving any CS presentations. Water was not available during the session and the waterspout was not illuminated.

Conditioning. One day after pre-exposure, rats were conditioned by two light-foot shock pairings, with the foot shock (1 mA/1 s) delivered immediately following the termination of the flashing light $(5 \mathrm{~s})$. The first light-shock pairing was presented after $5 \mathrm{~min}$ had elapsed and the second pairing $5 \mathrm{~min}$ after the first, followed by a further $5 \mathrm{~min}$ in the chamber, resulting in an overall session duration of $15 \mathrm{~min}$. Water was not available during the session and the waterspout was not illuminated for the duration of the session.

Reshaping. The day after conditioning, rats were reshaped using the same procedure as used during the initial shaping. This was to re-establish drinking behavior after the conditioning session. Latency to first lick during reshaping was used as a measure of contextual fear conditioning to the chamber (Nelson et al., 2011, 2013).

Test. The day after reshaping, rats underwent a test session to assess conditioning to the CS. During the test session, water was available throughout, and the waterspout was illuminated. Once the rats had performed 50 licks, the CS was presented continuously for $15 \mathrm{~min}$. The time taken to complete 50 licks before CS presentation (excluding latency to first lick) provides a measure of individual baseline variation (A period). This time was compared with the time taken to complete 50 licks during CS presentation (B period). A suppression ratio $[A /(A+B)]$ was used to assess the overall level of conditioning to the $\mathrm{CS}$, adjusted to individual variation in drinking, where a higher ratio represents a low level of fear conditioning (with a value of 0.5 or higher indicating no conditioning at all) and a ratio closer to 0 represents a high level of conditioning to the CS (Nelson et al., 2011, 2012).

\section{Verification of cannula placements}

After behavioral experiments, rats were deeply anaesthetized with sodium pentobarbital (Dolethal, Vetoquinol) and were transcardially perfused with $0.9 \%$ saline followed by $4 \%$ paraformaldehyde in saline. Subsequently brains were removed and stored in 4\% paraformaldehyde. Brains were sliced at $80-\mu \mathrm{m}$ thickness using a vibratome and placed on microscope slides. Injector placements were identified using light microscopy and mapped onto coronal sections of a rat brain atlas (Paxinos and Watson, 1998).

\section{Experimental design}

Both experiments 1 and 2 were run in a between-subjects design with a target sample size for both experiments of 16-18 per group. This sample size would give a power of $>80 \%$ to detect effect sizes of Cohen's $d=1$ for differences between groups (using between-subjects pairwise comparisons, two-tailed, with a significance threshold of $p<0.05$; G*Power; Faul et al., 2007), which has been suggested to be appropriate for neurobiological studies of aversive conditioning (Carneiro et al., 2018). Experiment 1 was run in three identical series, each including 24 rats. Experiment 2 was planned to comprise of two series, each containing 32 rats, but was ended after the first series. The second series was unnecessary, as there was clearly no evidence that the target effect size the study would have been powered for could be achieved (Neumann et al., 2017).

Rats were allocated to experimental groups according to a randomized block design. Two of the four rats in each cage were randomly assigned to the saline and the other two to the picrotoxin infusion group, and subsequently one rat of each pair was randomly assigned to either PE or NPE groups. The experimenters were blinded with respect to the infusion group allocation at the start of the experiment. In both experiments, several rats had to be excluded from the analysis of the whole experiment or some later stages of the experiment. During experiment 1 , 13 rats fell ill, with presumed meningitis, before reshaping, while a further two rats fell ill after reshaping and before the test session; two additional rats had blocked guide cannulae after surgery and before behavioral testing, resulting in exclusion from the experiment; another rat showed extended convulsive seizures after picrotoxin infusion before conditioning. During experiment 2, one rat died during surgery and a further three rats fell ill, with presumed meningitis, before the reshaping session. The final sample sizes contributing to the analysis of performance measures at the different test stages in experiments 1 and 2 are shown in Table 1.

In experiment $1, \mathrm{VH}$ drug infusions took place before both pre-exposure and conditioning sessions (Fig. 2A), whereas, in experiment 2, drug infusions took place before pre-exposure only (Fig. $3 A$ ). Rats were infused in batches of two pairs, by two experimenters, with each pair including one rat to receive saline and one rat to receive picrotoxin infusions. The two experimenters infused one pair, then the second pair, and testing started $10 \mathrm{~min}$ after the infusions for both rats of the second pair had been completed. This meant that all rats had a 10- to 15-min period between the end of the infusion and the start of behavioral testing. The timing of behavioral procedures after intracerebral infusions was based on electrophysiological measurements taken during VH infusion of picrotoxin (McGarrity et al., 2017) to capture the peak effect of hippocampal picrotoxin on neuronal firing following infusion.

\section{Statistical analysis}

The measures taken during the CER experiments were analyzed using a $2 \times 2$ ANOVA with between-subject 
Table 1: Final number of rats included in data analysis per group for each stage of both experiments

\begin{tabular}{lllll}
\hline & \multicolumn{2}{c}{ Experiment 1 } & \multicolumn{2}{c}{ Experiment 2 } \\
Group & Reshaping & Test & Reshaping & Test \\
\hline Saline NPE & 14 & 14 & 7 & 7 \\
Saline PE & 13 & 10 & 8 & 8 \\
Picrotoxin NPE & 15 & 15 & 6 & 6 \\
Picrotoxin PE & 17 & 17 & 7 & 7 \\
\hline
\end{tabular}

factors of pre-exposure group (NPE/PE) and drug infusion (saline/picrotoxin). All statistical tests and graphs were completed using SPSS (version 23), JASP (JASP Team: version 0.12.2, 2020) and GraphPad prism (version 7) software. The accepted level of significance was $p<0.05$. Raw latency data (time to first lick during reshaping) or time "A" data (time to 50 licks during test) were log transformed, as they showed unequal variance (Levene's test, all $F>5, p<0.002$ ), to ensure a normal distribution and suitability for parametric analysis (Nelson et al., 2011, 2012).

\section{Results}

\section{Cannula placements in the VH}

In both experiments, all cannula tips were located within the $\mathrm{VH}$, in coronal brain sections corresponding to between 4.3 and $6.3 \mathrm{~mm}$ posterior to bregma in the rat brain atlas by Paxinos and Watson (1998; Fig. 1). Many of the cannula placements, especially in experiment 1 (Fig. 1B) were located in the subiculum region of the $\mathrm{VH}$, corresponding to the coronal section at $6.3 \mathrm{~mm}$ posterior to bregma in the atlas by Paxinos and Watson (1998) and similar to other studies targeting the VH (Bardgett and Henry, 1999; Bast et al., 2001b; McGarrity et al., 2017). We did not target a particular subregion of the $\mathrm{VH}$, but note that the ventral subiculum together with the ventral CA1 region features overlapping functional connectivity to PFC and subcortical sites, including striatum, amygdala and septum (Groenewegen et al., 1987; Jay and Witter, 1991; Canteras and Swanson, 1992; Legault et al., 2000; Floresco et al., 2001; Dégenètais et al., 2003). As indicated in the Introduction and further considered in the Discussion, this functional connectivity is particularly relevant for the behavioral processes (fear conditioning and LI) investigated in the present study. It should also be noted that, although individual infusions may be placed in distinct subregions of the $\mathrm{VH}$, such as subiculum or CA1, the drug will spread beyond one subregion within the $\mathrm{VH}$. An infusion volume of $0.5 \mu \mathrm{l}$ (as used in the present study) will occupy a sphere with a radius of $0.5 \mathrm{~mm}$, if we assume isotropic spread of the infusion volume, and is likely to spread further, considering that spread is likely to be facilitated dorsally by the cannula tracks and diffusion will further add to drug spread (Jacobs et al., 2013). Previous multiunit electrophysiological recordings (McGarrity et al., 2017) showed that picrotoxin infusions into the $\mathrm{VH}$, using the same coordinates as in the present study, resulted in marked enhancement of neural burst firing recorded by a multielectrode array straddling various subregions of the $\mathrm{VH}$, including $\mathrm{CA} 1, \mathrm{CA} 3$, and dentate gyrus. In contrast, electrodes placed outside the medial and lateral boundaries of the $\mathrm{VH}$ did not reveal changes in neural firing, probably because of the densely packed fiber bundles surrounding the hippocampus (McGarrity et al., 2017). Therefore, the behavioral effects observed in the present study are likely to reflect disinhibition across several subregions of the $\mathrm{VH}$, although disinhibition in subiculum and CA1 regions may be particularly important, given that these regions feature much of the relevant functional connectivity to prefrontal and subcortical sites. Because a substantial number of infusion sites in the present study were placed within the subiculum region of the $\mathrm{VH}$, we include an additional analysis to explore whether key behavioral effects of $\mathrm{VH}$ disinhibition observed in the present study critically depended on cannula placements within the ventral subiculum.

\section{Experiment 1: VH disinhibition during preexposure and conditioning disrupts aversive conditioning Pretraining}

Analysis of latencies to lick at the end of pretraining, before pre-exposure, showed no overall effect of prospective infusion or pre-exposure group, nor an interaction of these factors (all $F_{(1,55)}<1$; data not shown).

\section{Reshaping}

VH picrotoxin, compared with saline, infusion reduced latencies to first lick after reintroduction to the conditioning context during the reshaping session in the NPE group, which reflects reduced contextual fear conditioning. In the PE group both saline and picrotoxin groups showed similarly low levels of contextual conditioning, as measured by short latencies to lick, which indicates that pre-exposure to the light CS reduced contextual conditioning in the saline group (Fig. 2B). These observations were supported by a significant infusion $\times$ pre-exposure interaction $\left(F_{(1,55)}=4.7, p=0.034\right)$. Further examination of the interaction by simple main effects analysis showed that hippocampal picrotoxin, compared with saline, reduced conditioning in the NPE group $\left(F_{(1,55)}=11.9\right.$, $p=0.001$ ), but this was not apparent in the PE group, because of a floor effect where both saline and picrotoxin rats showed similarly low conditioning $\left(F_{(1,55)}<1\right)$. In addition, pre-exposure to the CS reduced context conditioning in saline-infused rats, reflected by reduced latencies in the PE group as compared with the NPE group $\left(F_{(1,55)}=\right.$ $9.0, p=0.004)$. This effect was not present in picrotoxininfused rats $\left(F_{(1,55)}<1\right)$, probably reflecting a floor effect, i.e., the already low latencies in the picrotoxin rats.

Test

There was no difference in time to 50 licks before CS presentation (Time A) between infusion groups and preexposure groups (any effect or interaction involving infusion or pre-exposure: all $F<3, p>0.09$; data not shown). The group differences in latency to first lick that were evident at reshaping were not present during the test stage, probably reflecting extinguished contextual conditioning in the saline NPE group. The suppression ratios during the light test revealed that hippocampal disinhibition markedly 

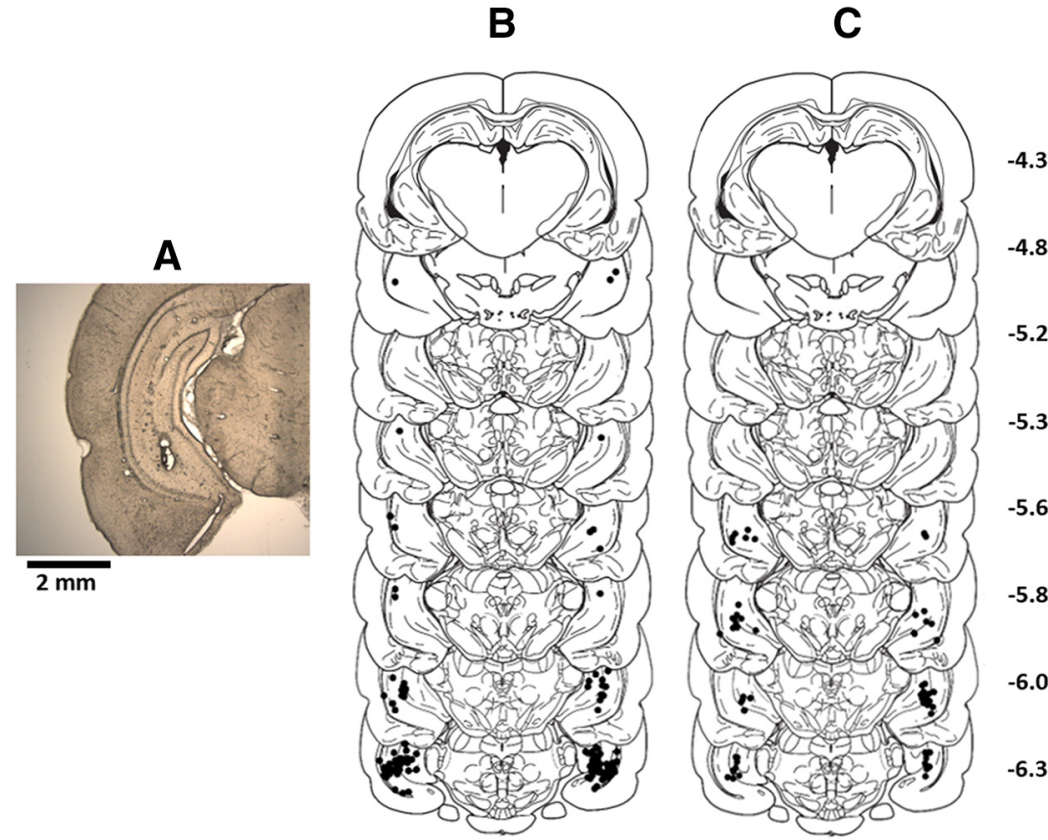

Figure 1. Infusion sites in the VH. $\boldsymbol{A}$, Illustrative coronal brain section showing infusion site in the VH. Approximate locations of infusion cannula tips (black dots) mapped onto coronal sections adapted from the Paxinos and Watson (1998) rat brain atlas for rats in experiments $1(\boldsymbol{B})$ and $2(\boldsymbol{C})$. Numbers on the right indicate posterior distance from bregma in millimeters.

disrupted conditioning to the CS in the NPE group, but did not affect conditioning in the PE group, i.e., there was no evidence that hippocampal disinhibition had affected LI (Fig. $2 C$ ). In saline-infused rats, the suppression ratio was markedly increased in the PE compared with the NPE group, reflecting reduced conditioning, i.e., LI (Fig. 2C, left). This difference between PE and NPE groups was not apparent in the picrotoxin-infused rats (Fig. $2 C$, right). However, this was because of picrotoxin-infused NPE rats showing markedly higher suppression ratios than saline-infused NPE rats, i.e., reduced conditioning to the light CS (compare white bars in Fig. 2C). In contrast, suppression ratios were similar in picrotoxin and saline-infused PE rats (Fig. 2C, compare gray bars). Thus, there was no evidence that hippocampal disinhibition reduced the impact of CS pre-exposure on conditioning. These observations were supported by a significant infusion $\times$ pre-exposure interaction $\left(F_{(1,52)}=4.142\right.$, $p=0.047$ ). Further examination of the interaction by simple main effects analysis revealed a main effect of infusion in the NPE group $\left(F_{(1,52)}=10.014, p=0.003\right)$ reflecting increased suppression ratio, i.e., reduced conditioning, caused by picrotoxin, compared with saline, whereas there was no effect of infusion in the PE group $\left(F_{(1,52)}<1\right)$. This resulted in the absence of a difference between PE and NPE in the picrotoxin-infused rats $\left(F_{(1,52)}<1\right)$, whereas saline-infused rats showed markedly higher suppression in the PE compared with the NPE group $\left(F_{(1,52)}=12.111, p=0.001\right)$.

\section{Experiment 2: VH disinhibition during preexposure alone does not affect conditioning or LI}

Pretraining

Analysis of latencies to lick at the end of pretraining, before pre-exposure, showed no overall effect of prospective infusion $\left(F_{(1,24)}=2.9, p=0.104\right)$ or pre-exposure group $\left(F_{(1,24)}<1\right)$, and there was no interaction of these factors $\left(F_{(1,24)}<1\right.$; data not shown).

\section{Reshaping}

Hippocampal picrotoxin infusion only at pre-exposure had no effect on conditioning to the context, as reflected by latencies to first lick during reshaping, and there was no difference between pre-exposure groups (all main effects and interactions, $F_{(1,24)}<1.5, p>0.2$; Fig. $3 B$ ). The latter contrasts with the finding in experiment 1 , that preexposure reduced latencies to first lick in saline-infused rats (Fig. 2B).

\section{Test}

There were no differences in the A period (time to 50 licks before CS presentation) between infusion and preexposure groups (all main effects and interactions, $F_{(1,24)}$ $<1.2, p>0.30$; data not shown). Both drug infusion groups showed similar fear conditioning to the light CS, reflected by similar suppression ratios, and robust LI, reflected by higher suppression ratios in the PE compared with the NPE groups (Fig. $3 C$ ). This was supported by an effect of pre-exposure group $\left(F_{(1,24)}=8.44, p=0.0078\right)$, without a main effect or interaction involving infusion group (both $F_{(1,24)}<1$ ).

\section{Seizure-related behavioral effects of hippocampal picrotoxin}

In several rats receiving hippocampal picrotoxin infusions in experiment 1 (20 out of 32 rats receiving picrotoxin) and experiment 2 (six out of 15 rats receiving picrotoxin), we observed seizure-related behavioral signs, 


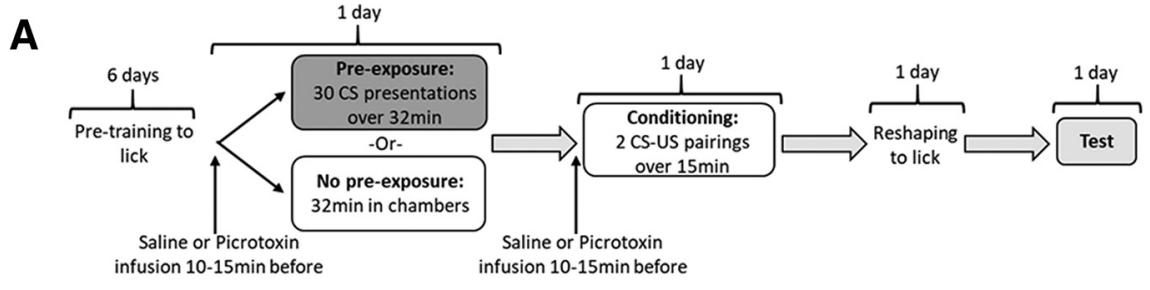

B

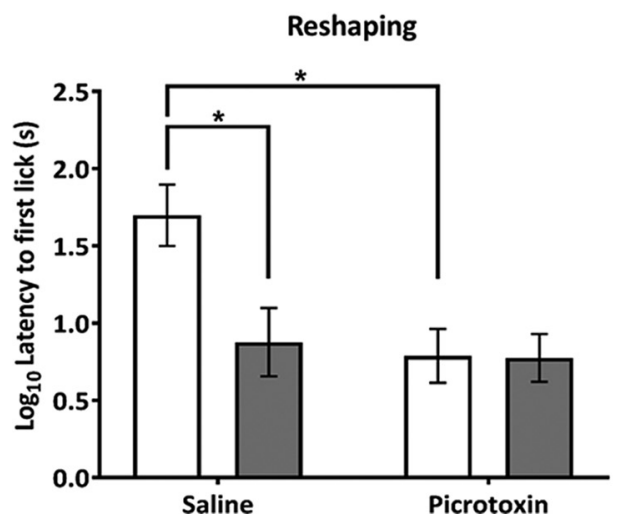

C

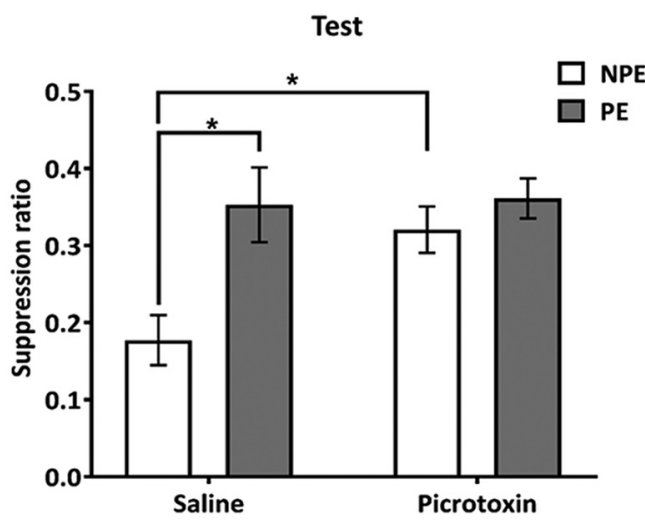

Figure 2. Experiment 1: ventral hippocampal disinhibition during pre-exposure and conditioning impairs the acquisition of contextual and elemental fear conditioning. $\boldsymbol{A}$, Design of experiment 1. $\boldsymbol{B}$, Mean ( \pm SEM) latency to first lick values (s; log transformed) in the conditioning chamber following the aversive conditioning session for NPE (white bars) and PE (gray bars) rats in the saline and picrotoxin groups. Saline NPE rats show longer latencies compared with all other groups indicating increased conditioning to the conditioning context. Picrotoxin-infused rats show reduced latencies compared with saline-infused animals indicating impaired conditioning to the conditioning context. C, Mean suppression ratio ( ${ }$ SEM) to the light CS for NPE (white) and PE (gray) rats in the saline and picrotoxin groups. Saline-infused rats displayed LI, with PE rats showing markedly less fear than NPE rats. Picrotoxininfused rats show similarly low levels of fear conditioning in both NPE and PE groups reflecting picrotoxin infusion abolished conditioning to the CS. Asterisks indicate statistically significant differences between groups $(F>9, p<0.005$; simple main effects analysis following significant interaction of infusion and pre-exposure).

including facial twitching, wet-dog shakes and wild running, which can often be observed before full motor seizures (Racine, 1972; Luttjohann et al., 2009). These effects were observed within $5 \mathrm{~min}$ after the end of the picrotoxin infusion. They typically subsided within $30-45 \mathrm{~min}$, after which rats showed no further adverse effects, with the exception of one rat, which showed continued uncontrollable clonic limb movement and was culled. We never observed these signs following saline infusions. Table 2 shows how many rats showed any of these seizure-related effects after the two picrotoxin infusions of experiment 1 or the one picrotoxin infusion of experiment 2. Although GABA network dysfunction, including in the hippocampus, is strongly implicated in the onset of seizures (Avoli and de Curtis, 2011), and the VH is a particularly seizure prone brain region, showing the earliest seizure activity in the pilocarpine rat model of seizures (Toyoda et al., 2013), previous studies using the same dose of picrotoxin as in the present study did not reveal seizure-related effects in Lister Hooded (McGarrity et al., 2017) or Wistar (Bast et al., 2001a) rats. Given that stress substantially facilitates hippocampal seizures (Joels, 2009; Manouze et al., 2019), the seizure-related effects of hippocampal picrotoxin infusions in the present study may reflect that, in contrast to previous studies involving hippocampal picrotoxin infusions, rats in the present study were exposed to water restriction and foot shocks as part of the CER procedure.

Importantly, additional analyses limited to the rats that did not show seizure-related behavioral signs during conditioning (saline NPE, $n=14$; saline PE, $n=10$; picrotoxin NPE, $n=10$; picrotoxin PE, $n=13$ ) still revealed a disruption of contextual and elemental fear conditioning in rats with VH disinhibition compared with saline-infused control rats in experiment 1 (Fig. 4). The pattern of changes in the measures of conditioning (latency to lick and suppression ratio, respectively) was virtually identical to the pattern revealed by the analysis including all rats (Fig. 2). More specifically, during reshaping, $\mathrm{VH}$ disinhibition in those rats that did not display seizure-related behavioral signs still reduced latencies to lick in the NPE group, reflecting reduced contextual fear conditioning (Fig. $4 A$ ). This was supported by a trend toward an interaction of infusion $\times$ pre-exposure $\left(F_{(1,46)}=3.614, p=0.0636\right)$ and a simple main effect of infusion in the NPE group $\left(F_{(1,46)}=\right.$ 5.330, $p=0.026)$. In addition, during test, $\mathrm{VH}$ picrotoxin reduced conditioned suppression (i.e., increased the suppression ratio) in response to the light CS in picrotoxin-infused NPE rats as compared with saline-infused NPE rats in those rats that did not display seizure-related behavioral signs (Fig. 4B). This was supported by a significant interaction of infusion $\times$ pre-exposure $\left(F_{(1,43)}=4.933\right.$, 
A

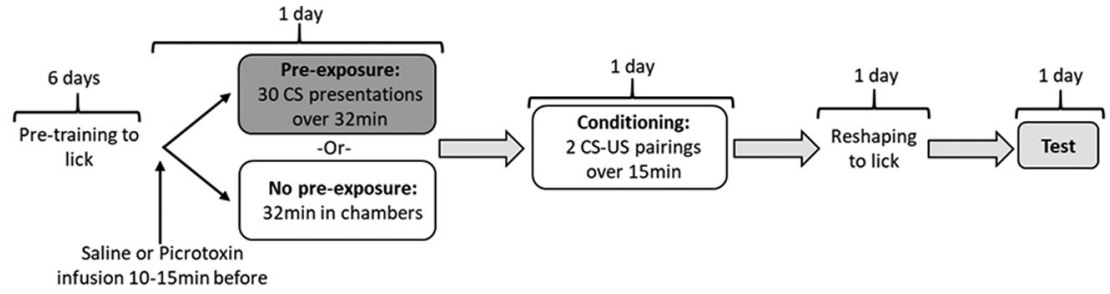

B

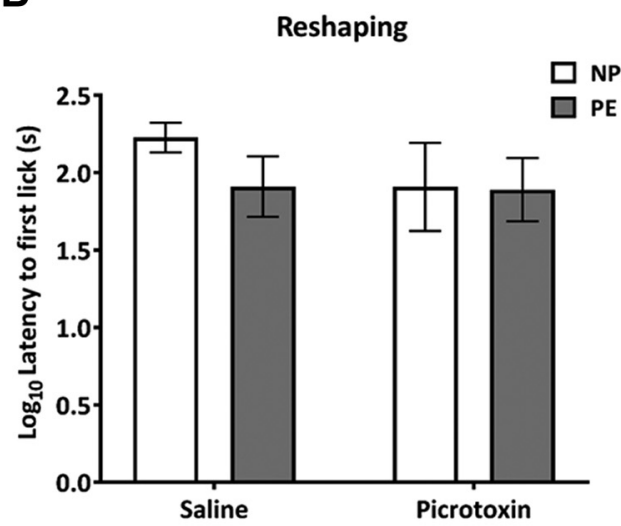

C

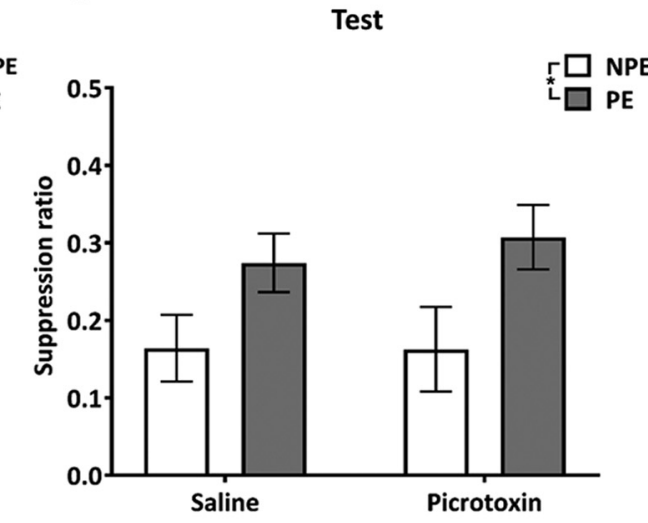

Figure 3. Experiment 2: VH disinhibition during pre-exposure does not impair the acquisition of LI. $\boldsymbol{A}$, Design of experiment 2, with the time point of the $\mathrm{VH}$ picrotoxin or saline infusion before the pre-exposure stage indicated. $\boldsymbol{B}$, Mean ( \pm SEM) latency to first lick (s; log transformed) in the conditioning chamber, during reshaping, following the aversive conditioning session for NPE (white bars) and PE (gray bars) rats in the saline and picrotoxin groups. All groups show similar levels of contextual conditioning, indicated by similar latencies to first lick. $\boldsymbol{C}$, Mean suppression ratio ( \pm SEM) to the light CS for control NPE (white) and PE (gray) rats in the saline and picrotoxin groups. Pre-exposure reduced fear responding to the CS in both saline and picrotoxin-infused rats compared with NPE rats, reflecting LI in both saline and picrotoxin-infused rats. Asterisk indicates significant main effect of pre-exposure during test $\left(F_{(1,24)}=8.44, p=0.008\right)$.

$p=0.0317)$ and a simple main effect of infusion in the NPE group $\left(F_{(1,43)}=8.310, p=0.006\right)$. Therefore, the disruption of fear conditioning by hippocampal disinhibition was not a consequence of seizure-related behavioral effects during conditioning.

\section{Placement of infusion sites in the ventral subiculum is not critical for the disruption of fear conditioning by VH disinhibition}

To explore whether the marked impairments in fear conditioning caused by $\mathrm{VH}$ disinhibition in experiment 1 depended on whether the infusion sites were located in the subiculum or other subregions in the $\mathrm{VH}$, we conducted an additional analysis, excluding data from rats with cannula placements in the ventral subiculum (i.e., placements within the coronal section corresponding to $6.3 \mathrm{~mm}$ posterior to bregma in Paxinos and Watson, 1998; see Fig. 1B). This analysis limited to rats with cannula placements outside the ventral subiculum (saline $\mathrm{NPE}, n=5$; saline PE, $n=5$; picrotoxin NPE, $n=5$; picrotoxin PE, $n=9$ ) revealed that picrotoxin infusions still disrupted fear conditioning as compared with saline-infused rats (Fig. 5). The changes seen in this subset of rats were very similar to the changes in latency to lick and suppression ratio seen in the analysis that included all rats (Fig. 2). More specifically, during reshaping picrotoxin reduced latency to lick as compared with saline-infused rats, reflecting reduced contextual conditioning (Fig. 5A), although this difference did not reach statistical significance (main effect of infusion: $F_{(1,22)}=2.076, p=0.1637$ ) reflecting limited statistical power because of the reduced sample

Table 2: Seizure-related behavioral signs observed after VH picrotoxin microinfusions

\begin{tabular}{lccccc}
\hline & & & \multicolumn{2}{c}{ Experiment 1 } \\
Observed behavior & Overall total & Experiment 1 total & Infusion 1 & Infusion 2 & Experiment 2 total \\
\hline Facial twitching & 3 & 3 & 1 & 2 & 0 \\
Wet dog shakes & 19 & 15 & 11 & 7 & 4 \\
Wild running & 10 & 9 & 8 & 2 & 1 \\
Clonic limb movement & 1 & 0 & 0 & 0 & 1
\end{tabular}

The type of behavior observed is indicated in column one. Total number of rats experiencing seizure-related behavior signs overall during experiment 1 or 2 is shown in column two. The number of rats experiencing seizure-related signs during experiment 1 is detailed in column 3 , with these signs separated to show the effects after the two individual infusions in columns 4 and 5 . Column 6 details the total number of rats showing seizure-related signs after the one infusion of experiment 2 . 
A

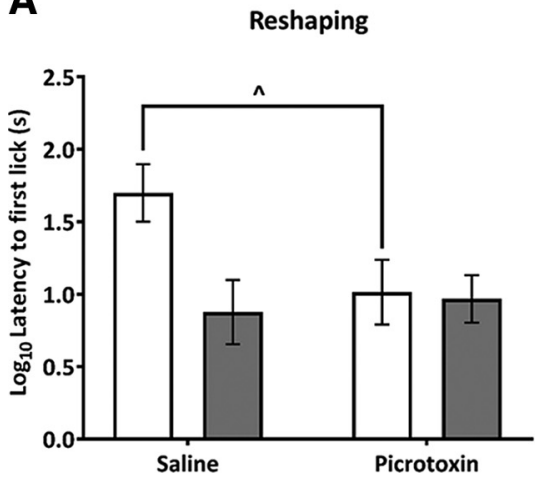

B

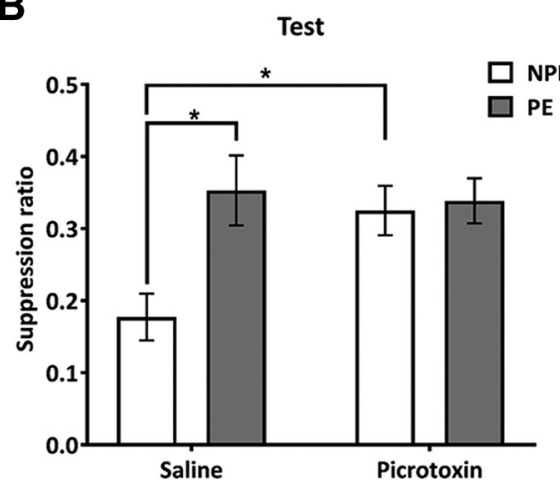

Figure 4. Experiment 1: an analysis limited to the rats that did not show seizure-related behavioral signs still reveals that ventral hippocampal disinhibition during pre-exposure and conditioning impairs the acquisition of contextual and elemental fear conditioning. $\boldsymbol{A}$, Mean ( \pm SEM) latency to first lick values (s; log transformed) in the conditioning chamber following the aversive conditioning session for NPE (white bars) and PE (gray bars) rats in the saline and picrotoxin groups. Saline NPE rats show longer latencies compared with all other groups indicating increased conditioning to the conditioning context, similar to the pattern of results obtained from the whole sample (compare Fig. $2 B$ ). B, Mean suppression ratios ( \pm SEM) to the light CS for NPE (white) and PE (gray) rats in the saline and picrotoxin groups. Picrotoxin-infused rats show similarly low levels of fear conditioning in both NPE and PE groups reflecting picrotoxin infusion abolished conditioning to the CS, very similar to the pattern of results obtained from the whole sample (compare Fig. 2C); $\wedge$ indicates statistically significant differences between saline and picrotoxin infused NPE rats $\left(F_{(1,46)}=5.330\right.$, $p=0.026$; simple main effects analysis following a trend toward interaction of infusion and pre-exposure, $\left.F_{(1,46)}=3.614, p=0.0636\right)$. Asterisks indicate statistically significant differences between groups $(F>8, p<0.01$; simple main effects analysis following significant interaction of infusion and pre-exposure).

size. In addition, during test, picrotoxin infusions reduced conditioned suppression in response to the light CS in NPE rats as compared with saline-infused NPE rats (Fig. 5B). This was supported by a significant interaction infusion $\times$ pre-exposure: $\left.F_{(1,22)}=6.226, p=0.0206\right)$ and a simple main effect of infusion in the NPE group $\left(F_{(1,22)}=9.221, p=0.006\right)$. Overall, this analysis suggests that the fear conditioning deficits reported in experiment 1 were not exclusively mediated by picrotoxin infusions placed in the ventral subiculum, but rather that VH disinhibition by picrotoxin infusions placed in other subregions of the $\mathrm{VH}$ similarly caused fear conditioning deficits.

\section{Discussion}

In experiment $1, \mathrm{VH}$ disinhibition by picrotoxin during pre-exposure and conditioning markedly reduced fear conditioning to the CS and, therefore, any reduction of fear conditioning in the PE compared with NPE group, which would indicate LI, could not be detected. Picrotoxin and saline-infused rats in the PE group did not differ, showing similarly low conditioning, which does not support the hypothesis that hippocampal disinhibition affected salience modulation. In addition to disrupting conditioning to the $\mathrm{CS}, \mathrm{VH}$ disinhibition also impaired
A

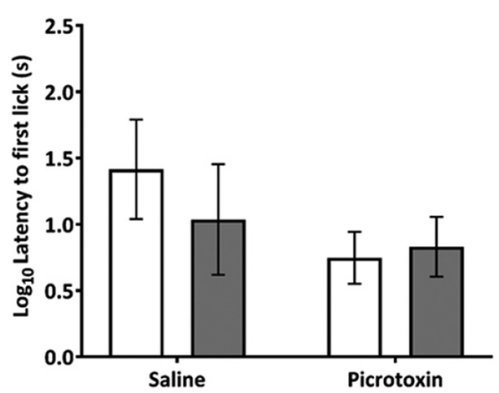

B

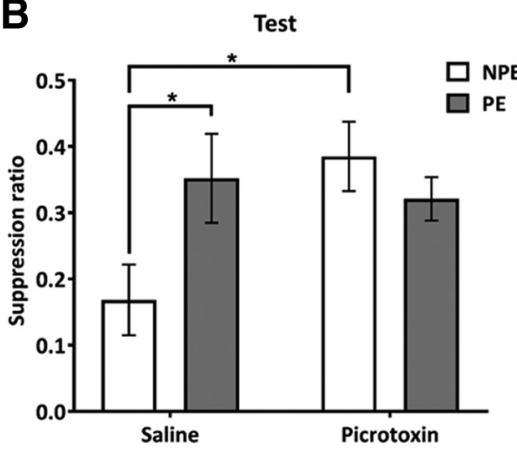

Figure 5. Experiment 1: data excluding rats with cannula placements in the ventral subiculum confirm that ventral hippocampal disinhibition during pre-exposure and conditioning impairs contextual and elemental fear conditioning. $\boldsymbol{A}$, Mean ( \pm SEM) latency to first lick values (s; log transformed) in the conditioning chamber following the aversive conditioning session for NPE (white bars) and PE (gray bars) rats in the saline and picrotoxin groups. Picrotoxin-infused rats show numerically reduced latencies as compared with saline-infused rats, especially in the NPE groups, indicating impaired conditioning to the context, similar to the pattern of results from the whole sample (compare Fig. $2 B$ ). $\boldsymbol{B}$, Mean suppression ratio ( \pm SEM) to the light CS for NPE (white) and PE (gray) rats in the saline and picrotoxin groups. Picrotoxin-infused rats show similarly low levels of fear conditioning in both NPE and PE groups reflecting picrotoxin infusion abolished conditioning to the CS. The pattern of results is very similar to the pattern obtained from the whole sample (compare Fig. $2 C)$. Asterisks indicate statistically significant differences between groups $(F>6, p<0.03$; simple main effects analysis following significant interaction of infusion and pre-exposure). 
contextual fear conditioning. In experiment 2 , which specifically examined the impact of hippocampal disinhibition during pre-exposure alone, there was no evidence for any impact on LI.

\section{Preexposure-induced reduction of contextual fear conditioning}

In experiment 1 , the saline-infused $\mathrm{PE}$ rats showed shorter latencies to the first lick than NPE rats, reflecting reduced fear conditioning to the context. This could reflect that the novelty of the light stimulus enhanced memory formation (Lisman and Grace, 2005; King and Williams, 2009; Duszkiewicz et al., 2019) in the NPE group. The reduced context conditioning in PE compared with NPE saline-infused rats was not evident in experiment 2 . This could be accounted for by a ceiling effect, i. e., higher levels of context conditioning, in experiment 2, which may have masked any further novelty-induced enhancement of context conditioning in the NPE group. In previous studies, un-operated rats showed stronger fear conditioning than cannulated rats that received hippocampal saline infusions, in terms of conditioned freezing (Zhang et al., 2001) and lick suppression (Zhang et al., 2000), suggesting that the infusion procedure itself, including the associated handling, might reduce fear conditioning. Therefore, the stronger conditioning in experiment 2 may partly reflect that, in contrast to experiment 1 , the rats did not receive drug infusions immediately before conditioning.

\section{VH disinhibition during preexposure and conditioning markedly reduces fear conditioning without affecting LI}

In experiment $1, \mathrm{VH}$ disinhibition during both pre-exposure and conditioning markedly reduced fear conditioning to the CS in the NPE group, resulting in similarly low levels of conditioning in both the NPE and PE groups. Whilst there was no evidence for $\mathrm{LI}$ following $\mathrm{VH}$ disinhibition, the absence of LI was not because of increased conditioning in the PE group, which would reflect aberrant salience allocation, but instead was because of reduced conditioning in the NPE group. Similar to the present study, Pouzet et al. (2004), using a comparable LI paradigm, demonstrated VH NMDA stimulation reduced conditioned suppression in the NPE group, although there was also some evidence for disrupted LI with a trend toward greater conditioned suppression in PE compared with NPE rats. Moreover, studies in the prenatal methylazoxymethanol acetate (MAM) rat model of schizophrenia, which shows a loss of parvalbumin GABA interneurons and hyperactivity in the $\mathrm{VH}$, also reported the absence of $\mathrm{LI}$, which was mediated by reduced conditioning in the NPE group (Flagstad et al., 2005; Lodge et al., 2009).

\section{Disruption of elemental and contextual fear conditioning by VH disinhibition might reflect disruption of regional and distal processing}

The impairments in fear conditioning to the CS and the context by VH disinhibition are likely mediated at the conditioning stage, which is supported by the finding in experiment 2 that disinhibition during pre-exposure alone did not affect conditioning. Impaired fear conditioning may reflect disrupted processing within the $\mathrm{VH}$ itself and in connected sites (Bast et al., 2017). Lesions, temporary inactivation by the sodium channel blocker TTX, and NMDA stimulation of the VH have been found to disrupt both contextual and elemental fear conditioning (Maren, 1999; Bast et al., 2001b; Zhang et al., 2001; Kjelstrup et al., 2002; Czerniawski et al., 2012). However, functional inhibition of the $\mathrm{VH}$ by the GABA agonist muscimol only disrupts contextual, but not elemental, conditioning, suggesting that neurons within the $\mathrm{VH}$ are mainly required for contextual fear conditioning (Bast et al., 2001b; Zhang et al., 2014). Therefore, the impaired contextual fear conditioning in the present study may reflect that disinhibition disrupts $\mathrm{VH}$ processing, whereas disrupted elemental fear conditioning is consistent with the idea that regional disinhibition can disrupt processing in $\mathrm{VH}$ projection sites (Bast et al., 2017), which have been implicated in elemental fear conditioning (see next paragraph). However, changes in dorsal hippocampal function, which is necessary for contextual fear conditioning and has been suggested to produce the underlying contextual representation (Anagnostaras et al., 2001; Bast et al., 2003; Matus-Amat et al., 2004; Hunsaker and Kesner, 2008), may also contribute to contextual fear conditioning deficits caused by $\mathrm{VH}$ disinhibition. VH disinhibition might disrupt dorsal hippocampal function by way of intrahippocampal inhibitory longitudinal connections (Sik et al., 1994, 1997). In line with this suggestion, a recent metabolic imaging study showed that VH disinhibition activated the VH but deactivated the dorsal hippocampus (Williams et al., 2019).

The $\mathrm{VH}$ also sends strong projections to the amygdala, mPFC, and septum (Risold and Swanson, 1997; Pitkanen et al., 2000; Cenquizca and Swanson, 2007; Hoover and Vertes, 2007), all of which are components of a brain circuit controlling conditioned fear responses to elemental stimuli (Tovote et al., 2015). The amygdala is a key component of the fear conditioning circuit and is thought to play a crucial role in the CS-US association and in conveying conditioned fear information to downstream effector sites (LeDoux, 2000; Duvarci and Pare, 2014). Thus, VH disinhibition, by causing aberrant drive of projections to the amygdala, could disrupt the processing of CS-US associations underlying conditioned fear. The mPFC is mainly thought to be required for the expression of cue conditioning and not its acquisition (Morgan et al., 1993; Pezze et al., 2003; Corcoran and Quirk, 2007), although inactivation of the rostral anterior cingulate cortex disrupted the acquisition of cue fear conditioning (Bissiere et al., 2008). The anterior cingulate cortex does not receive direct VH projections (Jay and Witter, 1991; Bian et al., 2019), but aberrant drive of $\mathrm{VH}$ projections to the mPFC might contribute to the disruption of elemental fear conditioning by way of regional connectivity within the mPFC (Jones et al., 2005). The lateral septum receives strong glutamatergic VH projections (Risold and Swanson, 1997; Cenquizca and Swanson, 2007) and is required for the 
acquisition of elemental fear conditioning (Calandreau et al., 2007). Additionally, hippocampo-lateral septum neurotransmission has been implicated in the modulation of the strength of CS-US associations and adaptive acquisition of conditioned fear responses (Desmedt et al., 2003; Calandreau et al., 2010). A recent neuroimaging study showed that $\mathrm{VH}$ disinhibition caused significant neural activation changes in the amygdala, mPFC, and LS (Williams et al., 2019) and, therefore, VH disinhibition could disrupt elemental fear conditioning by disrupting information processing at these projection sites.

In experiment 1 , the $\mathrm{VH}$ was disinhibited during pre-exposure and conditioning, but not during reshaping and test. Therefore, the impaired fear conditioning evident during reshaping and test sessions could reflect state dependence, i.e., that information learned in one neural state can, in some cases, only be retrieved/expressed in the same state (Overton, 1964). To rule this out would require showing that fear expression is disrupted if the $\mathrm{VH}$ is disinhibited both during conditioning and the test expression of fear, but the interpretation of this finding would be difficult because the $\mathrm{VH}$ has been implicated in the expression of conditioned fear (Sierra-Mercado et al., 2011). However, several studies have shown that state dependent learning does not account for the conditioning deficits caused by local drug microinfusions into specific brain sites, including the MPFC, amygdala, and dorsal hippocampus (Guarraci et al., 2000; Bast et al., 2003; Pezze et al., 2003). In addition, previous experiments using a similar 3-stage fear conditioning paradigm to study systemic drug effects on $\mathrm{LI}$ found no evidence for state-dependent effects (Barad et al., 2004). Another possibility that deserves consideration is that the reduced conditioned fear during reshaping and test in experiment 1 could reflect that $\mathrm{VH}$ disinhibition disrupted reactivity to and processing of the electric footshock. However, previous studies reported that neither inactivation, via a sodium channel blocker or a GABA agonist (McEown and Treit, 2009, 2010), nor electrical stimulation (Dringenberg et al., 2008) of VH disrupted reactivity to electric footshocks. In addition, based on our own anecdotal observations, all rats across treatment groups similarly vocalized and flinched/ jumped in response to foot shocks, although we did not systematically record and quantify these responses. Overall, a specific impairment in neural mechanisms underlying the formation of fear memory seems the most plausible account for the reduced conditioned suppression following VH disinhibition during conditioning.

\section{Hippocampal disinhibition during preexposure has no effect on the formation of $\mathrm{LI}$}

While aberrant dopamine transmission is thought to disrupt LI by interfering with the effect of pre-exposure during conditioning (Young et al., 2005; Morrens et al., 2020), stimulation and inhibition of GABA receptors disrupted LI formation at the pre-exposure stage (Feldon and Weiner, 1989; Lacroix et al., 2000). However, the lack of effect on $\mathrm{LI}$ acquisition by $\mathrm{VH}$ disinhibition during pre-exposure in experiment 2 suggests that sites outside the VH mediate the disruption of LI formation by systemic GABA receptor blockade during pre-exposure (Lacroix et al., 2000). Moreover, although VH disinhibition caused aberrant mPFC activation (Williams et al., 2019) and deficits in mPFC-dependent attention (McGarrity et al., 2017), our present findings show that $\mathrm{VH}$ disinhibition does not affect $\mathrm{mPFC}$-dependent processing involved in LI formation during pre-exposure (Lingawi et al., 2017, 2018). In line with this, mPFC disinhibition during pre-exposure and conditioning did not disrupt LI formation (Enomoto et al., 2011; Piantadosi and Floresco, 2014). This is consistent with the idea that different prefrontal functions can display distinct relationships to prefrontal neural activity (Bast et al., 2017), with LI formation disrupted only by reductions (Lingawi et al., 2018), but not increases (Enomoto et al., 2011; Piantadosi and Floresco, 2014), in prefrontal activity, whereas sustained attention requires balanced levels of prefrontal activity (Pezze et al., 2014).

Although the present experiments do not support the hypothesis that $\mathrm{VH}$ disinhibition during pre-exposure affects $\mathrm{LI}$, deactivation of the ventral subiculum during preexposure disrupted $\mathrm{LI}$ in a conditioned taste aversion paradigm, demonstrated by increased conditioning in the PE group (Peterschmitt et al., 2005, 2008). This suggests that LI formation normally requires the ventral subiculum during pre-exposure, but not balanced levels of ventral hippocampal activity.

\section{Clinical relevance}

Our findings do not support the hypothesis that VH disinhibition disrupts $\mathrm{LI}$ and thus do not provide evidence to suggest that hippocampal GABA dysfunction contributes to LI impairments in schizophrenia. However, acute pharmacological disruption of GABA-A receptor mediated inhibition by picrotoxin as used in the present study does not fully capture all aspects of anterior hippocampal GABA dysfunction present in schizophrenia (e.g., chronicity, disruption in GABAergic interneuron function, rather than postsynaptic GABA receptor dysfunction, etc.) and, thus, further work is required to elucidate how some of these aspects of hippocampal GABA dysfunction may impact on salience modulation. Apart from impairments in $\mathrm{LI}$ and other aspects of salience modulation (Roiser et al., 2009, 2013), fear conditioning deficits have been reported in schizophrenia (Holt et al., 2009, 2012). Such deficits were suggested to contribute to difficulties in differentiating relevant from irrelevant stimuli (Hofer et al., 2001; Jensen et al., 2008) and were associated with negative symptoms (Holt et al., 2012). Previous findings have implicated prefrontal disinhibition in aversive conditioning deficits in schizophrenia (Piantadosi and Floresco, 2014). Our findings suggest that hippocampal disinhibition also contributes to deficits in aversive conditioning.

\section{References}

Anagnostaras SG, Gale GD, Fanselow MS (2001) Hippocampus and contextual fear conditioning: recent controversies and advances. Hippocampus 11:8-17.

Avoli M, de Curtis M (2011) GABAergic synchronization in the limbic system and its role in the generation of epileptiform activity. Prog Neurobiol 95:104-132. 
Bannerman DM, Rawlins JN, McHugh SB, Deacon RM, Yee BK, Bast T, Zhang WN, Pothuizen HH, Feldon J (2004) Regional dissociations within the hippocampus-memory and anxiety. Neurosci Biobehav Rev 28:273-283.

Barad M, Blouin AM, Cain CK (2004) Like extinction, latent inhibition of conditioned fear in mice is blocked by systemic inhibition of Ltype voltage-gated calcium channels. Learn Mem 11:536-539.

Bardgett ME, Henry JD (1999) Locomotor activity and accumbens Fos expression driven by ventral hippocampal stimulation require D1 and D2 receptors. Neuroscience 94:59-70.

Baruch I, Hemsley DR, Gray JA (1988) Differential performance of acute and chronic schizophrenics in a latent inhibition task. J Nerv Ment Dis 176:598-606.

Bast T (2011) The hippocampal learning-behavior translation and the functional significance of hippocampal dysfunction in schizophrenia. Curr Opin Neurobiol 21:492-501.

Bast T, Zhang WN, Feldon J (2001a) Hyperactivity, decreased startle reactivity, and disrupted prepulse inhibition following disinhibition of the rat ventral hippocampus by the GABA(A) receptor antagonist picrotoxin. Psychopharmacology (Berl) 156:225-233.

Bast T, Zhang WN, Feldon J (2001b) The ventral hippocampus and fear conditioning in rats. Different anterograde amnesias of fear after tetrodotoxin inactivation and infusion of the GABA(A) agonist muscimol. Exp Brain Res 139:39-52.

Bast T, Zhang WN, Feldon J (2003) Dorsal hippocampus and classical fear conditioning to tone and context in rats: effects of local NMDA-receptor blockade and stimulation. Hippocampus 13:657675.

Bast T, Pezze M, McGarrity S (2017) Cognitive deficits caused by prefrontal cortical and hippocampal neural disinhibition. $\mathrm{Br} J$ Pharmacol 174:3211-3225.

Bian XL, Qin C, Cai CY, Zhou Y, Tao Y, Lin YH, Wu HY, Chang L, Luo CX, Zhu DY (2019) Anterior cingulate cortex to ventral hippocampus circuit mediates contextual fear generalization. J Neurosci 39:5728-5739.

Bissiere S, Plachta N, Hoyer D, McAllister KH, Olpe HR, Grace AA, Cryan JF (2008) The rostral anterior cingulate cortex modulates the efficiency of amygdala-dependent fear learning. Biol Psychiatry 63:821-831.

Calandreau L, Jaffard R, Desmedt A (2007) Dissociated roles for the lateral and medial septum in elemental and contextual fear conditioning. Learn Mem 14:422-429.

Calandreau L, Desgranges B, Jaffard R, Desmedt A (2010) Switching from contextual to tone fear conditioning and vice versa: the key role of the glutamatergic hippocampal-lateral septal neurotransmission. Learn Mem 17:440-443.

Canteras NS, Swanson LW (1992) Projections of the ventral subiculum to the amygdala, septum, and hypothalamus: a PHAL anterograde tract-tracing study in the rat. J Comp Neurol 324:180-194.

Carneiro CFD, Moulin TC, Macleod MR, Amaral OB (2018) Effect size and statistical power in the rodent fear conditioning literature - a systematic review. PLoS One 13:e0196258.

Cenquizca LA, Swanson LW (2007) Spatial organization of direct hippocampal field CA1 axonal projections to the rest of the cerebral cortex. Brain Res Rev 56:1-26.

Corcoran KA, Quirk GJ (2007) Activity in prelimbic cortex is necessary for the expression of learned, but not innate, fears. J Neurosci 27:840-844.

Czerniawski J, Ree F, Chia C, Otto T (2012) Dorsal versus ventral hippocampal contributions to trace and contextual conditioning: differential effects of regionally selective NMDA receptor antagonism on acquisition and expression. Hippocampus 22:1528-1539.

Dégenètais E, Thierry AM, Glowinski J, Gioanni Y (2003) Synaptic influence of hippocampus on pyramidal cells of the rat prefrontal cortex: an in vivo intracellular recording study. Cereb Cortex 13:782-792.

Desmedt A, Garcia R, Jaffard R (2003) An 8-day extensive elemental, but not contextual, fear conditioning potentiates hippocampal-lateral septal synaptic efficacy in mice. Synapse 49:270-278.
Dringenberg HC, Levine Y, Menard JL (2008) Electrical stimulation of dorsal, but not ventral hippocampus reduces behavioral defense in the elevated plus maze and shock-probe burying test in rats. Behav Brain Res 186:143-147.

Duszkiewicz AJ, McNamara CG, Takeuchi T, Genzel L (2019) Novelty and dopaminergic modulation of memory persistence: a tale of two systems. Trends Neurosci 42:102-114.

Duvarci S, Pare D (2014) Amygdala microcircuits controlling learned fear. Neuron 82:966-980.

Enomoto T, Tse MT, Floresco SB (2011) Reducing prefrontal gamma-aminobutyric acid activity induces cognitive, behavioral, and dopaminergic abnormalities that resemble schizophrenia. Biol Psychiatry 69:432-441.

Fanselow MS, Dong HW (2010) Are the dorsal and ventral hippocampus functionally distinct structures? Neuron 65:7-19.

Faul F, Erdfelder E, Lang AG, Buchner A (2007) G*Power 3: a flexible statistical power analysis program for the social, behavioral, and biomedical sciences. Behav Res Methods 39:175-191.

Feldon J, Weiner I (1989) Abolition of the acquisition but not the expression of latent inhibition by chlordiazepoxide in rats. Pharmacol Biochem Behav 32:123-127.

Flagstad P, Glenthøj BY, Didriksen M (2005) Cognitive deficits caused by late gestational disruption of neurogenesis in rats: a preclinical model of schizophrenia. Neuropsychopharmacology 30:250-260.

Floresco SB, Todd CL, Grace AA (2001) Glutamatergic afferents from the hippocampus to the nucleus accumbens regulate activity of ventral tegmental area dopamine neurons. J Neurosci 21:49154922.

Friston KJ, Liddle PF, Frith CD, Hirsch SR, Frackowiak RS (1992) The left medial temporal region and schizophrenia. A PET study. Brain 115:367-382.

Gray JA, Feldon J, Rawlins JNP, Smith AD, Hemsley DR (1991) The neuropsychology of schizophrenia. Behav Brain Sci 14:1-19.

Gray JA, Joseph MH, Hemsley DR, Young AMJ, Clea Warburton E, Boulenguez P, Grigoryan GA, Peters SL, Rawlins JNP, Taib CT, Yee BK, Cassaday H, Weiner I, Gal G, Gusak O, Joel D, Shadach E, Shalev U, Tarrasch R, et al. (1995) The role of mesolimbic dopaminergic and retrohippocampal afferents to the nucleus accumbens in latent inhibition: implications for schizophrenia. Behav Brain Res 71:19-31.

Groenewegen HJ, Vermeulen-Van der Zee E, te Kortschot A, Witter MP (1987) Organization of the projections from the subiculum to the ventral striatum in the rat. A study using anterograde transport of Phaseolus vulgaris leucoagglutinin. Neuroscience 23:103-120.

Guarraci FA, Frohardt RJ, Falls WA, Kapp BS (2000) The effects of intra-amygdaloid infusions of a D2 dopamine receptor antagonist on Pavlovian fear conditioning. Behav Neurosci 114:647-651.

Gwilt M, Bauer M, Bast T (2020) Frequency- and state-dependent effects of hippocampal neural disinhibition on hippocampal local field potential oscillations in anesthetized rats. Hippocampus 30:1021-1043

Heckers S, Konradi C (2015) GABAergic mechanisms of hippocampal hyperactivity in schizophrenia. Schizophr Res 167:4-11.

Hofer E, Doby D, Anderer P, Dantendorfer K (2001) Impaired conditional discrimination learning in schizophrenia. Schizophr Res 51:127-136.

Holt DJ, Lebron-Milad K, Milad MR, Rauch SL, Pitman RK, Orr SP, Cassidy BS, Walsh JP, Goff DC (2009) Extinction memory is impaired in schizophrenia. Biol Psychiatry 65:455-463.

Holt DJ, Coombs G, Zeidan MA, Goff DC, Milad MR (2012) Failure of neural responses to safety cues in schizophrenia. Arch Gen Psychiatry 69:893-903.

Hoover WB, Vertes RP (2007) Anatomical analysis of afferent projections to the medial prefrontal cortex in the rat. Brain Struct Funct 212:149-179.

Howes OD, Hird EJ, Adams RA, Corlett PR, McGuire P (2020) Aberrant salience, information processing, and dopaminergic signaling in people at clinical high risk for psychosis. Biol Psychiatry 88:304-314. 
Hunsaker MR, Kesner RP (2008) Dissociations across the dorsalventral axis of CA3 and CA1 for encoding and retrieval of contextual and auditory-cued fear. Neurobiol Learn Mem 89:61-69.

Jacobs NS, Allen TA, Nguyen N, Fortin NJ (2013) Critical role of the hippocampus in memory for elapsed time. J Neurosci 33:1388813893.

Jay TM, Witter MP (1991) Distribution of hippocampal CA1 and subicular efferents in the prefrontal cortex of the rat studied by means of anterograde transport of Phaseolus vulgaris-leucoagglutinin. J Comp Neurol 313:574-586.

Jensen J, Willeit M, Zipursky RB, Savina I, Smith AJ, Menon M, Crawley AP, Kapur S (2008) The formation of abnormal associations in schizophrenia: neural and behavioral evidence. Neuropsychopharmacology 33:473-479.

Joels M (2009) Stress, the hippocampus, and epilepsy. Epilepsia 50:586-597.

Jones BF, Groenewegen HJ, Witter MP (2005) Intrinsic connections of the cingulate cortex in the rat suggest the existence of multiple functionally segregated networks. Neuroscience 133:193-207.

Joseph MH, Peters SL, Moran PM, Grigoryan GA, Young AMJ, Gray JA (2000) Modulation of latent inhibition in the rat by altered dopamine transmission in the nucleus accumbens at the time of conditioning. Neuroscience 101:921-930.

Kapur S (2003) Psychosis as a state of aberrant salience: a framework linking biology, phenomenology, and pharmacology in schizophrenia. Am J Psychiatry 160:13-23.

Katzel D, Wolff AR, Bygrave AM, Bannerman DM (2020) Hippocampal hyperactivity as a druggable circuit-level origin of aberrant salience in schizophrenia. Front Pharmacol 11:486811.

King SO 2nd, Williams CL (2009) Novelty-induced arousal enhances memory for cued classical fear conditioning: interactions between peripheral adrenergic and brainstem glutamatergic systems. Learn Mem 16:625-634.

Kjelstrup KG, Tuvnes FA, Steffenach HA, Murison R, Moser El, Moser MB (2002) Reduced fear expression after lesions of the ventral hippocampus. Proc Natl Acad Sci USA 99:10825-10830.

Lacroix L, Spinelli S, Broersen LM, Feldon J (2000) Blockade of latent inhibition following pharmacological increase or decrease of GABA(A) transmission. Pharmacol Biochem Behav 66:893-901.

LeDoux JE (2000) Emotion circuits in the brain. Annu Rev Neurosci 23:155-184.

Legault M, Rompré PP, Wise RA (2000) Chemical stimulation of the ventral hippocampus elevates nucleus accumbens dopamine by activating dopaminergic neurons of the ventral tegmental area. $\mathrm{J}$ Neurosci 20:1635-1642.

Lieberman JA, Girgis RR, Brucato G, Moore H, Provenzano F, Kegeles L, Javitt D, Kantrowitz J, Wall MM, Corcoran CM, Schobel SA, Small SA (2018) Hippocampal dysfunction in the pathophysiology of schizophrenia: a selective review and hypothesis for early detection and intervention. Mol Psychiatry 23:1764-1772.

Lingawi NW, Westbrook RF, Laurent V (2017) Extinction and latent inhibition involve a similar form of inhibitory learning that is stored in and retrieved from the infralimbic cortex. Cereb Cortex 27:5547-5556.

Lingawi NW, Holmes NM, Westbrook RF, Laurent V (2018) The infralimbic cortex encodes inhibition irrespective of motivational significance. Neurobiol Learn Mem 150:64-74.

Lisman JE, Grace AA (2005) The hippocampal-VTA loop: controlling the entry of information into long-term memory. Neuron 46:703713.

Lisman JE, Coyle JT, Green RW, Javitt DC, Benes FM, Heckers S, Grace AA (2008) Circuit-based framework for understanding neurotransmitter and risk gene interactions in schizophrenia. Trends Neurosci 31:234-242.

Lodge DJ, Grace AA (2011) Hippocampal dysregulation of dopamine system function and the pathophysiology of schizophrenia. Trends Pharmacol Sci 32:507-513.

Lodge DJ, Behrens MM, Grace AA (2009) A loss of parvalbumin-containing interneurons is associated with diminished oscillatory activity in an animal model of schizophrenia. J Neurosci 29:23442354.

Luttjohann A, Fabene PF, van Luijtelaar G (2009) A revised Racine's scale for PTZ-induced seizures in rats. Physiol Behav 98:579-586.

Manouze $\mathrm{H}$, Ghestem A, Poillerat V, Bennis M, Ba-M'hamed S, Benoliel JJ, Becker C, Bernard C (2019) Effects of single cage housing on stress, cognitive, and seizure parameters in the rat and mouse pilocarpine models of epilepsy. eNeuro 6:ENEURO.017918.2019.

Maren S (1999) Neurotoxic or electrolytic lesions of the ventral subiculum produce deficits in the acquisition and expression of Pavlovian fear conditioning in rats. Behav Neurosci 113:283-290.

Matus-Amat P, Higgins EA, Barrientos RM, Rudy JW (2004) The role of the dorsal hippocampus in the acquisition and retrieval of context memory representations. J Neurosci 24:2431-2439.

McEown K, Treit D (2009) The role of the dorsal and ventral hippocampus in fear and memory of a shock-probe experience. Brain Res 1251:185-194.

McEown K, Treit D (2010) Inactivation of the dorsal or ventral hippocampus with muscimol differentially affects fear and memory. Brain Res 1353:145-151.

McGarrity S, Mason R, Fone KC, Pezze M, Bast T (2017) Hippocampal neural disinhibition causes attentional and memory deficits. Cereb Cortex 27:4447-4462.

McHugo M, Talati P, Armstrong K, Vandekar SN, Blackford JU, Woodward ND, Heckers S (2019) Hyperactivity and reduced activation of anterior hippocampus in early psychosis. Am J Psychiatry 176:1030-1038.

Mitchell SN, Yee BK, Feldon J, Gray JA, Rawlins JN (2000) Activation of the retrohippocampal region in the rat causes dopamine release in the nucleus accumbens: disruption by fornix section. Eur $\mathrm{J}$ Pharmacol 407:131-138.

Morgan MA, Romanski LM, LeDoux JE (1993) Extinction of emotional learning: contribution of medial prefrontal cortex. Neurosci Lett 163:109-113.

Morrens J, Aydin C, Janse van Rensburg A, Esquivelzeta Rabell J, Haesler S (2020) Cue-evoked dopamine promotes conditioned responding during learning. Neuron 106:142-153.e7.

Nelson AJ, Thur KE, Marsden CA, Cassaday HJ (2011) Dopamine in nucleus accumbens: salience modulation in latent inhibition and overshadowing. J Psychopharmacol 25:1649-1660.

Nelson AJ, Thur KE, Cassaday HJ (2012) Dopamine D1 receptor involvement in latent inhibition and overshadowing. Int $\mathrm{J}$ Neuropsychopharmacol 15:1513-1523.

Nelson AJD, Thur KE, Marsden CA, Cassaday HJ (2013) Paradoxical effects of low dose MDMA on latent inhibition in the rat. Neuropharmacology 67:331-336.

Neumann K, Grittner U, Piper SK, Rex A, Florez-Vargas O, Karystianis G, Schneider A, Wellwood I, Siegerink B, loannidis JP, Kimmelman J, Dirnagl U (2017) Increasing efficiency of preclinical research by group sequential designs. PLoS Biol 15:e2001307.

Overton DA (1964) State-dependent or "dissociated" learning produced with pentobarbital. J Comp Physiol Psychol 57:3-12.

Paxinos G, Watson C (1998) A stereotaxic atlas of the rat brain. New York: Academic.

Peleg-Raibstein D, Pezze MA, Ferger B, Zhang WN, Murphy CA, Feldon J, Bast T (2005) Activation of dopaminergic neurotransmission in the medial prefrontal cortex by $\mathrm{N}$-methyl-d-aspartate stimulation of the ventral hippocampus in rats. Neuroscience 132:219232.

Peterschmitt Y, Hoeltzel A, Louilot A (2005) Striatal dopaminergic responses observed in latent inhibition are dependent on the hippocampal ventral subicular region. Eur J Neurosci 22:2059-2068.

Peterschmitt Y, Meyer F, Louilot A (2008) Differential influence of the ventral subiculum on dopaminergic responses observed in core and dorsomedial shell subregions of the nucleus accumbens in latent inhibition. Neuroscience 154:898-910.

Pezze MA, Bast T, Feldon J (2003) Significance of dopamine transmission in the rat medial prefrontal cortex for conditioned fear. Cereb Cortex 13:371-380. 
Pezze M, McGarrity S, Mason R, Fone KC, Bast T (2014) Too little and too much: hypoactivation and disinhibition of medial prefrontal cortex cause attentional deficits. J Neurosci 34:7931-7946.

Piantadosi PT, Floresco SB (2014) Prefrontal cortical GABA transmission modulates discrimination and latent inhibition of conditioned fear: relevance for schizophrenia. Neuropsychopharmacology 39:2473-2484.

Pitkanen A, Pikkarainen M, Nurminen N, Ylinen A (2000) Reciprocal connections between the amygdala and the hippocampal formation, perirhinal cortex, and postrhinal cortex in rat. A review. Ann NY Acad Sci 911:369-391.

Pouzet B, Zhang WN, Weiner I, Feldon J, Yee BK (2004) Latent inhibition is spared by $\mathrm{N}$-methyl-D-aspartate (NMDA)-induced ventral hippocampal lesions, but is attenuated following local activation of the ventral hippocampus by intracerebral NMDA infusion. Neuroscience 124:183-194.

Qaddoumi MG, Ananthalakshmi KV, Phillips OA, Edafiogho IO, Kombian SB (2014) Evaluation of anticonvulsant actions of dibromophenyl enaminones using in vitro and in vivo seizure models. PLoS One 9:e99770.

Racine RJ (1972) Modification of seizure activity by electrical stimulation. II. Motor seizure. Electroencephalogr Clin Neurophysiol 32:281-294.

Rascle C, Mazas O, Vaiva G, Tournant M, Raybois O, Goudemand $M$, Thomas $P$ (2001) Clinical features of latent inhibition in schizophrenia. Schizophr Res 51:149-161.

Risold PY, Swanson LW (1997) Connections of the rat lateral septal complex. Brain Res Brain Res Rev 24:115-195.

Roiser JP, Stephan KE, den Ouden HE, Barnes TR, Friston KJ, Joyce EM (2009) Do patients with schizophrenia exhibit aberrant salience? Psychol Med 39:199-209.

Roiser JP, Howes OD, Chaddock CA, Joyce EM, McGuire P (2013) Neural and behavioral correlates of aberrant salience in individuals at risk for psychosis. Schizophr Bull 39:1328-1336.

Romaniuk L, Honey GD, King JR, Whalley HC, Mclntosh AM, Levita L, Hughes M, Johnstone EC, Day M, Lawrie SM, Hall J (2010) Midbrain activation during Pavlovian conditioning and delusional symptoms in schizophrenia. Arch Gen Psychiatry 67:1246-1254.

Sierra-Mercado D, Padilla-Coreano N, Quirk GJ (2011) Dissociable roles of prelimbic and infralimbic cortices, ventral hippocampus, and basolateral amygdala in the expression and extinction of conditioned fear. Neuropsychopharmacology 36:529-538.

Sik A, Ylinen A, Penttonen M, Buzsaki G (1994) Inhibitory CA1-CA3hilar region feedback in the hippocampus. Science 265:17221724

Sik A, Penttonen M, Buzsaki G (1997) Interneurons in the hippocampal dentate gyrus: an in vivo intracellular study. Eur J Neurosci 9:573-588.
Strange BA, Witter MP, Lein ES, Moser El (2014) Functional organization of the hippocampal longitudinal axis. Nat Rev Neurosci 15:655-669.

Tamminga CA, Stan AD, Wagner AD (2010) The hippocampal formation in schizophrenia. Am J Psychiatry 167:1178-1193.

Tan Z, Robinson HL, Yin DM, Liu Y, Liu F, Wang H, Lin TW, Xing G, Gan L, Xiong WC, Mei L (2018) Dynamic ErbB4 activity in hippocampal-prefrontal synchrony and top-down attention in rodents. Neuron 98:380-393.e4.

Tovote P, Fadok JP, Luthi A (2015) Neuronal circuits for fear and anxiety. Nat Rev Neurosci 16:317-331.

Toyoda I, Bower MR, Leyva F, Buckmaster PS (2013) Early activation of ventral hippocampus and subiculum during spontaneous seizures in a rat model of temporal lobe epilepsy. J Neurosci 33:11100-11115.

Tregellas JR, Smucny J, Harris JG, Olincy A, Maharajh K, Kronberg E, Eichman LC, Lyons E, Freedman R (2014) Intrinsic hippocampal activity as a biomarker for cognition and symptoms in schizophrenia. Am J Psychiatry 171:549-556.

Weiner I (2003) The "two-headed" latent inhibition model of schizophrenia: modeling positive and negative symptoms and their treatment. Psychopharmacology (Berl) 169:257-297.

Williams S, Hock R, Oelschelegel O, Goldschmidt J, Bast T (2019) Brain-wide activation changes caused by hippocampal neural disinhibition [abstract]. BNA Festival of Neuroscience 2019. Brain Neurosci Adv 3.

Young AM, Moran PM, Joseph MH (2005) The role of dopamine in conditioning and latent inhibition: what, when, where and how? Neurosci Biobehav Rev 29:963-976.

Zhang WN, Bast T, Feldon J (2000) Microinfusion of the non-competitive N-methyl-d-aspartate receptor antagonist MK-801 (dizocilpine) into the dorsal hippocampus of Wistar rats does not affect latent inhibition and prepulse inhibition, but increases startle reaction and locomotor activity. Neuroscience 101:589-599.

Zhang WN, Bast T, Feldon J (2001) The ventral hippocampus and fear conditioning in rats: different anterograde amnesias of fear after infusion of $\mathrm{N}$-methyl-D-aspartate or its noncompetitive antagonist MK-801 into the ventral hippocampus. Behav Brain Res 126:159-174.

Zhang WN, Bast T, Xu Y, Feldon J (2014) Temporary inhibition of dorsal or ventral hippocampus by muscimol: distinct effects on measures of innate anxiety on the elevated plus maze, but similar disruption of contextual fear conditioning. Behav Brain Res 262:47-56. 